\title{
INTERAÇÃO EDUCADORA-CRIANÇA EM CRECHES PÚBLICAS: ESTILOS LINGUÍSTICOS ${ }^{1}$
}

\author{
Deborah Dornellas Ramos \\ Nádia Maria Ribeiro Salomão*
}

\begin{abstract}
RESUMO. O presente estudo teve o objetivo de analisar a interação educadora-criança em creches públicas, considerando os estilos linguísticos das educadoras e a comunicação infantil. O estudo dos estilos linguísticos destaca-se nas análises das interações entre adultos e crianças, especialmente em se tratando daquelas da faixa etária em torno dos 24 meses, devido à emergência das primeiras pequenas frases. Participaram do estudo seis educadoras e doze crianças com idade entre 23 e 25 meses, que frequentavam creches públicas de João Pessoa, Paraíba. As interações entre educadora e criança foram observadas sistematicamente em contextos diádicos e poliádicos de leitura. Categorias interacionais foram elaboradas a posteriori, para a análise dos dados. As educadoras utilizaram mais estilos associados à promoção do desenvolvimento linguístico nos contextos diádicos, enquanto os estilos relacionados à direção e ao controle dos comportamentos predominaram nos contextos poliádicos. As análises consideraram a influência mútua entre os estilos comunicativos e o nível de desenvolvimento linguístico infantil, além dos aspectos contextuais.
\end{abstract}

Palavras-chave: Interação educador-criança; creche; desenvolvimento infantil.

\section{CHILD-EDUCATOR'S INTERACTIONS AT PUBLIC DAY-CARES: LINGUISTIC STYLES}

\begin{abstract}
This study analyzed the child-educator interactions at public daycares, considering the educators' linguistic styles and the children's communication. The studies about the linguistic styles are relevant for adult-child interactions, especially around the age of 24 months, due to the emergency of the first short sentences. It included 6 educators and 12 children aged between 23 and 25 months, attending public daycares in João Pessoa, Paraíba. The child-educator interactions were systematically observed dyadic contexts and polyadic reading. Interactional categories were elaborated à posteriori, for data analysis. The educators used more styles associated with the promotion of language development in dyadic contexts, while the styles related to the direction and to the behavior control predominated in polyadic contexts. The analysis considered the mutual influence between communicative styles and children's level of language development, beyond the contextual aspects.
\end{abstract}

Key words: Child-educator Interaction; public daycare; child development.

\section{INTERACCIÓN EDUCADORA-NIÑO EN GUARDERÍAS PÚBLICAS: ESTILOS LINGÜÍSTICOS}

RESUMEN. El presente estudio analizó la interacción educadora-niño en guarderías públicas, considerando los estilos lingüísticos de las educadoras y la comunicación infantil. El estudio de los estilos lingüísticos se destaca en el análisis de las interacciones adulto-niño, especialmente sobre los 24 meses, debido la emergencia de las primeras pequeñas frases. Participaron 6 educadoras y 12 niños, con edad entre 23 y 25 meses, en guarderías públicas de João Pessoa, Paraíba. Las interacciones se observaron sistemáticamente en contextos diádicos y poliádicos de lectura. Se elaboraron categorías interaccionales a posteriori para el análisis de los datos. Las educadoras utilizaron más estilos asociados a la promoción del desarrollo lingüístico en los contextos diádicos, mientras los estilos relacionados con la dirección y con el control de los comportamientos predominaron en los contextos poliádicos. Los análisis consideraron la influencia mutua entre los estilos comunicativos y el nivel de desarrollo linguístico infantil, además de los aspectos contextuales.

Palabras-clave: Interacción educadora-niño; guardería; desarrollo del niño.

Apoio: CAPES.

Mestre em Psicologia pela Universidade Federal da Paraíba (2010); doutoranda em Psicologia Social, pela mesma instituição, Brasil.

\# Doutora em Psicologia pela University of Manchester -Inglaterra (1996); pós-doutora pela University of North CarolinaCharlotte (EUA); professora do Departamento de Psicologia e do Programa de Pós-Graduação em Psicologia Social da Universidade Federal da Paraíba, Brasil. 
A interação entre as crianças e as pessoas com quem elas convivem é vista, na perspectiva da interação social dos estudiosos da linguagem, como um fator essencial para o desenvolvimento linguístico infantil, uma vez que é por meio das trocas com os adultos que os bebês estabelecem suas primeiras formas de comunicação e têm acesso à linguagem falada pelas pessoas em seu meio (Phillips, 1973; Snow, 1972, 1994). Deste modo, a necessidade do outro enquanto referencial para a aprendizagem da língua faz destacar-se o papel dos adultos como parceiros comunicativos iniciais das crianças e a influência que as educadoras exercem sobre o desenvolvimento linguístico daquelas que frequentam as creches.

Especialmente no caso das creches públicas, onde muitas das crianças despendem parte considerável do seu tempo interagindo e se comunicando nestes ambientes, as educadoras atuam como suas parceiras comunicativas de nível mais avançado. Isso faz dessas profissionais uma importante referência comunicativa para as crianças que desde cedo frequentam as instituições de educação e cuidado infantil. No caso daquelas que se encontram em torno dos 24 meses de idade, a importância destas interações sobressai, devido à emergência das primeiras pequenas frases, o que leva esta faixa etária a ser considerada como um período crítico no desenvolvendo linguístico (Rescorla, 1989, 2009).

Sendo assim, a elaboração destes enunciados iniciais sofrerá forte influência dos estilos comunicativos aos quais as crianças têm acesso. Destaca-se ainda que determinados estilos - como as reformulações, as expansões, os feedbacks e os contextos de atenção conjunta, por exemplo - possuem propriedades facilitadoras do desenvolvimento linguístico (Girolametto, Weitzman \& Greenberg, 2003; Tomasello, Carpenter, Call, Behne, \& Moll, 2005; Fonsêca \& Salomão, 2006; Wong, Moran, \& Foster-Cohen, 2012), enquanto outros, como os diretivos, são vistos com mais ressalva, uma vez que são observadas controvérsias quanto à adequação do seu uso. $\mathrm{O}$ motivo disto é que a fala diretiva se caracteriza por enunciados nos quais os adultos expressam comandos ou ordens, com o intuito tanto de obter a atenção da criança e direcioná-la quanto de enfatizar algo que lhe foi solicitado e dirigir o seu comportamento (Snow, 1994; Braz Aquino \& Salomão, 2005).

Assim, as controvérsias que envolvem a diretividade da fala remetem ao fato de esta ser identificada como inibidora do desenvolvimento linguístico infantil, em virtude de seus enunciados serem considerados mais restritivos e intrusivos. Não obstante se observa que, em situações específicas, a fala também pode relacionar-se positivamente com o desenvolvimento linguístico infantil, sobretudo quando se trata de crianças de faixa etária menor ou com problemas de desenvolvimento, em função da sua estrutura mais simples e de seu conteúdo de fácil interpretação (Salomão, 2010). É importante ressaltar que, à medida que a competência linguística das crianças se desenvolve, estes enunciados tendem a se modificar e a frequência do seu uso costuma diminuir.

Partindo da relevância dos estilos comunicativos e suas relações com o desenvolvimento da linguagem infantil, o objetivo deste estudo foi analisar as interações entre educadoras e crianças em creches públicas, considerando os estilos linguísticos utilizados pelas educadoras e a participação comunicativa das crianças na faixa etária em torno dos 24 meses nesses contextos interativos.

Destaca-se que a capacidade dos estilos comunicativos de apresentar um potencial facilitador do desenvolvimento linguístico infantil depende de algumas características presentes na fala e nos comportamentos dos adultos, como, por exemplo, a responsividade, que remete à capacidade do adulto para cuidar da criança, mostrando-se sensível aos seus sinais e gestos, ou seja, percebendo-os e respondendo adequadamente, por meio de trocas comunicativas recíprocas. (Girolametto \& Weitzman, 2002; Fonseca \& Salomão, 2006; Bressani, Bosa, \& Lopes, 2007; Cabell et al, 2011).

Neste contexto, a responsividade é fundamental para que o diálogo estabelecido com a criança possua sintonia e seja semanticamente contingente, o que consiste em combinar imediatamente o enunciado com o conteúdo ou tópico falado pela criança, resultando, assim, na continuidade da conversação e em maiores oportunidades de participação infantil no diálogo (Fonseca \& Salomão, 2006; Bressani, Bosa, \& Lopes, 2007).

No que diz respeito à interação entre a educadora e a criança, Clarke-Stewart e Alhussen (2002) realizaram uma ampla revisão dos estudos que abordavam o tema e tiveram como resultado que a qualidade da atenção dirigida pelas educadoras é fundamental para o estabelecimento das interações, sugerindo que aquelas profissionais que se mostravam mais envolventes e responsivas promoviam melhor o desenvolvimento das crianças que interagiam com elas. Além disso, as crianças apresentavam habilidades sociais e intelectuais mais avançadas quando as suas cuidadoras possuíam nível educacional mais elevado, eram mais respeitosas e estimulantes e ofereciam experiências educacionais variadas, principalmente as linguísticas.

Em se tratando das experiências linguísticas, constatou-se ainda que as crianças cujas educadoras falavam e se comunicavam mais, desenvolviam 
melhor o seu potencial comunicativo e pontuavam melhor em testes de inteligência. As educadoras que também eram mais responsivas aos questionamentos infantis, menos diretivas e menos críticas, e que utilizavam mais reforços positivos do que negativos, costumavam ter alunos que se saíam melhor em testes de inteligência e aprendizagem, concentrando-se mais em suas tarefas e brincando em níveis mais complexos (Clarke-Stewart \& Alhussen, 2002).

É importante ressaltar que a responsividade e a qualidade da atenção dispensada pelas educadoras relacionam-se a algumas variáveis de ordem contextual, como a qualidade das creches e a proporção de crianças por adultos nas salas de aula, o que, por sua vez, implica em repercussões sobre a qualidade do desenvolvimento das crianças, especialmente sobre o desenvolvimento linguístico (Clark-Stewart \& Alhussen, 1997; Burchinal, Roberts, Riggins, Zeissel, Neeb, \& Bryant, 2000; Girolametto \& Weitzman, 2002; Cabell et al, 2011).

Bressani, Bosa e Lopes (2007) chegaram à mesma conclusão quando estudaram a responsividade entre educadora e bebê no contexto brasileiro. Nesse estudo verificaram que a o número de crianças por educadora foi um fator de influência peculiar sobre a responsividade da educadora na instituição que investigaram, uma vez que a educadora precisava interagir com crianças de diferentes faixas etárias e níveis de desenvolvimento em uma mesma sala de aula, realidade que é comum nas instituições de educação e cuidado infantil do País.

Os feedbacks e as reformulações são especialmente relevantes para a promoção do desenvolvimento linguístico, pois permitem às crianças um meio de comparação entre a sua linguagem, menos desenvolvida, e a linguagem utilizada pelos adultos, possibilitando às crianças apreender os elementos linguísticos que faltam em seus enunciados (Leonard, Camarata, Pawlowska, Brown, \& Camarata, 2006; Leonard, Camarata, Pawlowska, Brown, \& Camarata; 2008).

Com relação à presença das reformulações e dos feedbacks nas falas das educadoras, Hargrave e Sénéchal (2000), em um estudo desenvolvido em creches que atendiam crianças de baixo nível socioeconômico no Canadá, verificaram que durante as interações em sala de aula as educadoras utilizavam poucos feedbacks, reformulações e requisições de respostas gerais, cujo caráter facilitador do desenvolvimento linguístico deve-se ao fato de conferirem às crianças a oportunidade de aprimorar suas habilidades comunicativas, uma vez que implicam em respostas mais amplas e melhor estruturadas, quando comparadas às requisições de respostas específicas, por exemplo, que costumam suscitar respostas mais simples e restritas ao "sim" ou "não".

Hargrave e Sénéchal (2000) observaram também que os contextos de interação diádica levaram a ganhos mais significativos tanto no aprendizado de novos vocábulos quanto no desenvolvimento do vocabulário expressivo, concluindo que os ganhos mais limitados durante as interações em sala de aula podem ter resultantes da necessidade de as educadoras compartilharem a sua atenção com muitas crianças simultaneamente, ocasionando tanto o comprometimento da atenção quanto o da responsividade.

Na mesma direção, Girolametto e Weitzman (2002), em um estudo desenvolvido com crianças entre dois e três anos de idade, matriculadas em creches e pré-escolas canadenses, verificaram que as educadoras frequentemente engajavam as crianças em diálogos e seguiam as suas iniciativas; no entanto, as profissionais raramente reformulavam ou expandiam as sentenças das crianças, raramente prolongavam o diálogo no sentido de esclarecer ou informar, e não respondiam de forma adequada ao seu nível de desenvolvimento linguístico.

Estes resultados sugeriram que a linguagem apresentada pelas educadoras seria direcionada às crianças em termos dos tópicos abordados, mas limitada com relação às oportunidades de extensão conversacional e ao uso de respostas semanticamente contingentes. Tais aspectos também foram observados no estudo desenvolvido por Marinac, Ozanne e Woodyat (2000), que, ao investigarem a linguagem utilizada por educadoras durante a interação com crianças em creches australianas, verificaram que suas falas não se adaptavam nem à idade nem ao nível de desenvolvimento linguístico das crianças, diferentemente do que geralmente ocorre com as díades mãe-criança.

Outra característica marcante na linguagem utilizada pelas educadoras enquanto interagem com as crianças é a diretividade da fala. No que se refere, especialmente, aos contextos de interação coletiva com as crianças mais novas, os diretivos costumam facilitar o manejo do grupo e o controle dos comportamentos infantis, promovendo, ao mesmo tempo, interação e segurança (Girolametto, Weitzman, \& Greenberg, 2003). Não obstante, mesmo que inicialmente esse tipo de input encoraje a interação com o grupo, a longo prazo ele tende a inibir a produtividade verbal das crianças, pois a fala diretiva geralmente não promove a extensão do diálogo, exige poucas demandas cognitivas e costuma não ser adequada ao nível de desenvolvimento infantil (Snow, 1994).

Verifica-se, destarte, que existem controvérsias quanto ao papel da diretividade na comunicação estabelecida com as crianças. Uma possível explicação 
recai no fato de existirem diversos subtipos de diretivos, cujas repercussões sobre o desenvolvimento linguístico variam de acordo com o contexto em que são utilizados, com a idade das crianças e com seu nível de desenvolvimento linguístico e cognitivo (Girolametto, Weitzman, Lieshout, \& Duff, 2000; Braz Aquino \& Salomão, 2005; Salomão, 2010).

Entre os fatores que se associam ao uso dos diretivos na comunicação com as crianças destaca-se o nível educacional dos adultos (Hoff, Laursen, \& Tardiff, 2002; Hoff, 2006; Rowe, 2008). Em um estudo que investigava a relação entre a escolaridade de educadoras e a diretividade da fala, Girolametto, Weitzman \& Greenberg (2003) observaram que as profissionais que haviam recebido algum treinamento ou formação em desenvolvimento infantil tendiam a interagir de forma mais responsiva com as crianças, enquanto aquelas que não possuíam nenhum preparo neste sentido tendiam a ser mais diretivas.

Outro fator muitas vezes associado ao uso excessivo de diretivos é o nível socioeconômico dos adultos, que frequentemente pode estar relacionado ao nível educacional. Sob este aspecto, os estudos sugerem que os adultos que possuem níveis educacionais e socioeconômicos mais elevados, costumam falar mais com as crianças, utilizar um vocabulário mais vasto e dirigir menos o seu comportamento (Hoff, 2006; Rowe, 2008).

Além da baixa escolaridade e do baixo nível socioeconômico, as práticas de cuidado, fiscalização e controle dos comportamentos infantis também se relacionam ao uso dos diretivos. A causa disto é que a principal função desse estilo linguístico consiste em expressar comandos ou ordens, com o intuito de dirigir a atenção das crianças e de enfatizar algo que está sendo solicitado (Snow, 1994). Neste sentido, é importante mencionar a pesquisa realizada por Lordelo (1998), que, ao investigar as práticas e concepções de educadoras que trabalhavam em uma creche pública de Salvador, verificou que estas profissionais ainda se encontravam presas à concepção de que a creche seria um ambiente mais voltado para o cuidar do que para o educar, por isso priorizavam em suas práticas as atividades mais ligadas ao cuidado físico e ao controle dos comportamentos.

Tendo em vista que o baixo nível educacional e socioeconômico costuma caracterizar o perfil das educadoras que trabalham nas creches públicas brasileiras, especialmente no Nordeste do país (Instituto Nacional de Estudos e Pesquisas Educacionais Anísio Teixeira, 2003), bem como das famílias das crianças que frequentam estas instituições (Instituto Brasileiro de Geografia e Estatística, 2007), é importante considerar o fato de estas variáveis estarem associadas a repercussões negativas sobre o desenvolvimento linguístico infantil. Além disso, é preciso considerar também que as peculiaridades encontradas no desenvolvimento linguístico das crianças pertencentes aos diferentes níveis socioeconômicos se relacionam com as concepções das pessoas sobre o desenvolvimento da linguagem e com o próprio uso que é feito dela em contexto (Hoff, 2006).

Destarte, é possível afirmar que as variáveis contextuais perpassam as interações estabelecidas com as crianças e exercem influência sobre os diversos aspectos das suas vidas, entre os quais se destaca o seu desenvolvimento linguístico. Sendo assim, o presente estudo buscou analisar as interações entre educadoras e crianças em creches públicas, com o intuito de verificar os estilos linguísticos utilizados pelas educadoras e a participação e desempenho nas interações por parte das crianças da faixa etária em torno dos 24 meses.

\section{MÉTODO}

\section{Participantes}

A interação entre educadora e criança foi observada em seis instituições públicas de educação infantil da cidade de João Pessoa, Paraíba. Participaram do estudo doze crianças na faixa etária entre 23 e 25 meses, e seis educadoras, que eram responsáveis pelas turmas de Maternal I nestas instituições.

\section{Instrumentos}

Os instrumentos utilizados para a realização da pesquisa foram uma câmara de vídeo digital, para registrar as observações das interações, e um gravador de áudio digital, para o registro das entrevistas feitas com as educadoras.

\section{Procedimentos}

As interações entre a educadora e a criança primeiro foram observadas em contextos poliádicos, que consistiram na leitura de livros utilizados rotineiramente em sala de aula, com a participação das educadoras responsáveis e de todas as crianças das turmas do maternal. Estes contextos foram utilizados por possibilitarem o acesso às estratégias de comunicação utilizadas pelas educadoras durante uma atividade que fazia parte da rotina das creches.

Posteriormente, as interações foram observadas em contextos diádicos de leitura, que consistiram na leitura de um livro de histórias infantis escolhido pela pesquisadora e contaram com a participação das seis 
educadoras e de doze crianças de idade entre 23 e 25 meses, com o intuito de verificar o uso das pequenas frases e o desenvolvimento vocabular dessas crianças. É importante salientar que, durante a observação e o registro das interações, a pesquisadora procurou interferir o mínimo possível no ambiente.

Além das observações, foram realizadas entrevistas semiestruturadas para estabelecer rapport com as educadoras, obter seus dados sociodemográficos e informações gerais acerca da rotina das creches e das crianças, bem como apreender as concepções das educadoras sobre o desenvolvimento infantil.

\section{Análise dos dados}

As observações dos contextos interativos foram transcritas segundo as normas do CHAT (Codes for Human Analysis of Transcripts), que faz parte do programa computacional CHILDES (Child Language
Data Exchange System). Posteriormente, foram elaboradas categorias interacionais para os comportamentos comunicativos das educadoras (Apêndice A), o que possibilitou que fossem obtidas as frequências desses comportamentos por meio do CLAN (Computerised Language Analysis), que também compõe o programa CHILDES.

\section{RESULTADOS E DISCUSSÃO}

Para a apreciação dos principais dados elencados durante as interações educadora-criança, nos contextos diádicos e poliádicos, apresenta-se a seguir a tabela 1, contendo as frequências e os percentuais totais dos estilos linguísticos utilizados pelas educadoras.

Tabela 1 - Estilos Linguísticos Dirigidos Pelas Educadoras nos Contextos de Interação Diádica e Poliádica

\begin{tabular}{|c|c|c|c|c|c|}
\hline \multirow[b]{2}{*}{ Categorias } & \multirow[b]{2}{*}{ Subcatergorias } & \multicolumn{2}{|c|}{ Contexto diádico } & \multicolumn{2}{|c|}{ Contexto poliádico } \\
\hline & & $f$ & $\%$ & $f$ & $\%$ \\
\hline Assertivos & & 448 & 17,60 & 328 & 33,40 \\
\hline Total & & 448 & 17,60 & 328 & 33,40 \\
\hline Reformulações & & 16 & 0,62 & 2 & 0,20 \\
\hline Total & & 16 & 0,62 & 2 & 0,20 \\
\hline \multirow[t]{4}{*}{ Diretivos } & Diretivo de atenção & 842 & 33,08 & 224 & 22,81 \\
\hline & Diretivo de controle & 13 & 0,51 & 63 & 6,41 \\
\hline & Diretivo de instrução precisa & 72 & 2,82 & 15 & 1,52 \\
\hline & Diretivo de instrução imprecisa & 34 & 1,33 & 3 & 0,30 \\
\hline Total & & 961 & 37,76 & 305 & 31,05 \\
\hline \multirow[t]{5}{*}{ Feedbacks } & Feedback de aprovação & 99 & 3,88 & 16 & 1,62 \\
\hline & Feedback de desaprovação & 9 & 0,35 & 0 & 0 \\
\hline & Feedback de correção & 12 & 0,47 & 0 & 0 \\
\hline & Feedback de confirmação & 6 & 0,23 & 2 & 0,20 \\
\hline & $\begin{array}{l}\text { Feedback de resposta à } \\
\text { questão }\end{array}$ & 1 & 0,03 & 2 & 0,20 \\
\hline Total & & 127 & 4,99 & 20 & 2,03 \\
\hline \multirow[t]{5}{*}{$\begin{array}{l}\text { Requisi- } \\
\text { ções }\end{array}$} & $\begin{array}{l}\text { Requisição de resposta } \\
\text { específica }\end{array}$ & 464 & 18,23 & 139 & 14,15 \\
\hline & Requisição de resposta geral & 236 & 9,27 & 60 & 6,10 \\
\hline & Requisição de sugestão & 74 & 2,90 & 16 & 1,62 \\
\hline & Requisição de esclarecimento & 6 & 0,23 & 1 & 0,10 \\
\hline & Requisição de complementação & 17 & 0,66 & 3 & 0,30 \\
\hline Total & & 797 & 31,31 & 219 & 22,30 \\
\hline Imitações & & 2 & 0,07 & 1 & 0,10 \\
\hline Total & & 2 & 0,07 & 1 & 0,10 \\
\hline \multirow{2}{*}{$\begin{array}{l}\text { Expressão } \\
\text { de afeto }\end{array}$} & Acariciar & 3 & 0,11 & 0 & 0 \\
\hline & Sorrir & 36 & 1,41 & 4 & 0,40 \\
\hline Total & & 39 & 1,53 & 4 & 0,40 \\
\hline Total & & 2545 & 99,97 & 982 & 99,96 \\
\hline
\end{tabular}


A partir da tabela 1, é possível verificar que, nos contextos diádicos as educadoras comunicaram-se mais com as crianças do que nos contextos poliádicos, tendo os contextos diádicos apresentado mais que o dobro da frequência de enunciados, quando comparados aos contextos poliádicos.

Resultado semelhante a este foi encontrado no estudo desenvolvido por Hargrave e Séchénal (2000), os quais investigaram os efeitos da leitura de livros infantis em crianças de creches canadenses que apresentavam atraso no desenvolvimento vocabular. No estudo, constatou-se que durante as interações nos contextos diádicos as educadoras também se comunicavam com maior frequência. Além disso, elas despendiam mais tempo interagindo com as crianças nesses contextos do que nas situações de leitura coletiva. Segundo as autoras, esta diferenciação pode ser reflexo da própria natureza dos contextos, uma vez que a interação diádica seria capaz de proporcionar trocas mais ricas, além de maior participação das crianças.

Outro dado que sobressaiu no presente estudo foi a prevalência dos estilos diretivos na linguagem utilizada pelas educadoras. Destaca-se que existem diferentes tipos de diretivos e que estes exercem sua influência sobre o desenvolvimento linguístico de diferentes maneiras (Girolametto, Weitzman, Lieshout, \& Duff, 2000; Braz Aquino \& Salomão, 2005; Salomão, 2010). Os diretivos de atenção, por exemplo, apesar de se basearem no princípio de mudança do foco atencional da criança em função do foco de interesse do adulto, podem contribuir na medida em que sejam utilizados com o intuito de manter a criança concentrada na interação e promover a sua participação, enquanto o uso dos diretivos de controle, apesar do seu caráter restritivo, pode ser necessário em situações que remetem à manutenção da segurança das próprias crianças, por exemplo, especialmente em se tratando das menos desenvolvidas.

Pôde-se observar que, tanto nos contextos diádicos quanto nos poliádicos, houve uma frequência elevada dos diretivos de atenção, correspondendo a $33,8 \%$ do total dos enunciados nos contextos diádicos e $22,81 \%$ nos contextos poliádicos. No caso das crianças da faixa etária das que participaram do presente estudo, a alta incidência dos diretivos de atenção pode ser vista como reflexo do próprio nível de desenvolvimento das habilidades comunicativas infantis e da necessidade de as educadoras manterem a atenção das crianças direcionada aos contextos interativos (Girolametto, Weitzman, Lieshout, \& Duff, 2000; Braz Aquino \& Salomão, 2005; Salomão, 2010).

Destaca-se também que, apesar de os diretivos de atenção terem sobressaído, a frequência dos diretivos de controle foi bem maior nos contextos poliádicos em comparação aos contextos diádicos. Ainda no que concerne ao uso dos diretivos pelas educadoras nas creches, o estudo realizado por Girolametto, Weitzman, Lieshout e Duff (2000) sugere que o uso destes estilos comunicativos associa-se também às interações em contextos coletivos, nos quais costumam facilitar o manejo do grupo e o controle dos comportamentos das crianças.

É importante ressaltar ainda que nos depoimentos prestados nas entrevistas realizadas com as educadoras que participaram do estudo prevaleceram as falas referentes às atividades de rotina das creches, dotadas de um caráter voltado mais para o cuidado e a orientação de condutas. $\mathrm{Na}$ mesma direção, também foram frequentes as falas cujo conteúdo remetia a uma percepção de caráter negativo acerca dos comportamentos das crianças, bem como sobressaíram as falas nas quais as educadoras atribuíram a si mesmas o papel de mãe das crianças.

Assim, tanto os dados apreendidos nas entrevistas como os que emergiram a partir das observações das interações indicaram que as práticas das educadoras que participaram do estudo encontravam-se mais voltadas para o cuidado, o controle e a fiscalização das crianças. Isto também foi observado no estudo desenvolvido por Lordelo (1998), ao verificar a prevalência do caráter cuidador nos discursos e nas práticas de educadoras em creches públicas de Salvador.

Outra informação importante é que o uso dos diretivos encontra-se ainda associado ao baixo nível educacional e socioeconômico dos adultos (Girolametto, Weitzman, \& Greenberg, 2003; Hoff, 2006; Rowe, 2008). Neste sentido, cumpre ressaltar que a renda média familiar das educadoras que participaram deste estudo encontrava-se entre dois e quatro salários mínimos. Destaca-se também que, das seis entrevistadas, apenas duas apresentavam formação de nível superior, dado este relevante, visto que o nível educacional pouco elevado é uma das características que compõem o perfil das educadoras das creches públicas brasileiras, especialmente na Região Nordeste (Instituto Brasileiro de Geografia e Estatística, 2007). 
Com relação aos estilos comunicativos, houve também uma alta incidência dos estilos assertivos na linguagem utilizada pelas educadoras, denotando $17,60 \%$ dos enunciados nos contextos diádicos e $33,40 \%$ das expressões utilizadas nos contextos poliádicos. Ainda no que concerne aos assertivos, nota-se que, nos contextos poliádicos, este foi o estilo comunicativo mais frequente, com incidência maior até que a dos diretivos, os quais representaram $31,05 \%$ do total de expressões presentes nestes contextos.

Neste sentido, é importante citar a pesquisa desenvolvida por Girolametto e Weitzman (2002), que, ao estudarem a responsividade educadoracriança em um contexto de brincadeira com massa de modelar e em outro de leitura de livros, revelaram que as educadoras utilizaram mais assertivos nos contextos coletivos de leitura, prevalecendo as sentenças cujo intuito era informar e/ou classificar.

De acordo com os autores, este resultado pode ser reflexo do fato de as educadoras, em contextos coletivos de leitura, terem o hábito de se prender mais aos textos, por verem nesta atividade um caráter didático e instrucional, o que as levaria a preocuparse mais em informar, descrever e classificar. Sobre este aspecto, as educadoras nutrem, por vezes, a expectativa de que as crianças se atenham mais a escutar, prestar atenção e responder às questões específicas relacionadas aos livros, adotando assim uma postura mais passiva.

Neste estudo, as requisições também se destacaram nas falas das profissionais, especialmente as requisições de respostas específicas e as de respostas gerais, sendo esses dois tipos mais frequentes nos contextos diádicos do que nos poliádicos. Além disso, ressalta-se que as requisições de respostas específicas prevaleceram em ambos os contextos, quando comparadas às requisições de resposta geral, que são consideradas promotoras do desenvolvimento linguístico.

Esses resultados corroboram os da pesquisa realizada por Rivera, Girolametto, Greenberg e Weitzman (2005), que, ao investigarem, em uma creche da região metropolitana de Toronto, no Canadá, os diferentes tipos de requisições utilizados pelas educadoras e a responsividade das crianças, revelaram que as requisições de respostas específicas prevaleceram quando comparadas às requisições de resposta geral, em contextos onde as educadoras interagiam com crianças em grupo.
No que concerne à maior frequência das requisições de respostas gerais nos contextos de interação diádica, Hargrave e Séchénal (2000) observaram, assim como se constatou no presente estudo, que as requisições de respostas gerais e os feedbacks eram bem mais frequentes nos contextos diádicos em comparação aos contextos coletivos. Segundo os autores, isto pode ser reflexo do fato de os contextos diádicos possibilitarem às educadoras a oportunidade de dedicar mais atenção às crianças e utilizar estilos de linguagem capazes de promover melhor o desenvolvimento linguístico das mesmas.

Diante disto, é importante refletir também acerca dos comportamentos comunicativos apresentados pelas crianças uma vez que foi realizada aqui uma apreciação geral dos estilos linguísticos utilizados pelas educadoras.

No que diz respeito à participação das crianças nas interações dos contextos diádicos, é preciso salientar que, entre as doze crianças que participaram do estudo, prevaleceram as respostas não verbais quando a criança responde de forma não verbal (gestualmente, ou movimentando a cabeça de forma afirmativa ou negativa, por exemplo) - além dos comportamentos de apontar e olhar em direção à professora. Tais apontamentos sugerem que as crianças possuem a sua linguagem compreensiva bem desenvolvida, corroborando os dados elencados nas entrevistas realizadas com as educadoras, tendo em vista que as profissionais consideraram satisfatório o desenvolvimento da linguagem compreensiva das crianças.

Neste sentido, o estudo desenvolvido por Hunttenlocher, Vasilyeva, Cymerman e Levine (2002), que compararam os níveis de compreensão entre crianças de baixo nível socioeconômico, matriculadas em creches públicas, e crianças de nível socioeconômico elevado, indicou que ao final do ano letivo não havia diferenciação significativa quanto ao desempenho das crianças. Isto sugere que aquelas que frequentavam as creches públicas não apresentavam maiores prejuízos quanto ao desenvolvimento desta habilidade específica, assim como foi observado no estudo em questão. Por outro lado, a mesma pesquisa apontou que o desenvolvimento das habilidades sintáticas nas crianças se relacionava à proporção de sentenças complexas emitidas pelas suas educadoras, sugerindo que a complexidade das falas das profissionais se refletia sobre o desenvolvimento das habilidades sintáticas infantis. 
Com relação à complexidade da fala das educadoras que participaram do presente estudo, verificou-se nos contextos diádicos que estas profissionais fizeram uso de sentenças complexas com maior frequência. É o caso das requisições de respostas gerais, que tiveram uma incidência de $f=236$ nas interações diádicas e $f=60$ nas poliádicas; contudo é preciso atentar para o fato de a rotina das creches públicas ser marcada pela interação quase constante em contextos poliádicos, devido à alta proporção de crianças por adulto.

A quantidade elevada de crianças nas salas de aula termina por induzir as educadoras a utilizarem uma comunicação menos responsiva (Marinac, Ozanne, \& Woodyat, 2000; Bressani, Bosa, \& Lopes, 2007; Cabell et al., 2011), usando um índice elevado de assertivos (Girolametto \& Weitzman, 2002), com o intuito de informar, descrever e classificar. Isso leva as crianças a assumirem uma postura mais passiva, detendo-se aos comportamentos de escutar e prestar atenção, o que também está relacionado aos índices mais altos de diretivos de controle (Girolametto, Weitzman, Lieshout, \& Duff, 2000).

É preciso também salientar que o alto número de crianças interagindo com as educadoras nos contextos coletivos está associado a um índice mais baixo de feedbacks de aprovação, de reformulações e de requisições de respostas gerais (Hargrave \& Séchénal, 2000), bem como a uma menor qualidade e quantidade de atenção (Clark-Stewart \& Alhussen, 1997; Burchinal et al, 2000; Bressani, Bosa, \& Lopes, 2007).

Estes dados são de fundamental importância para a pesquisa em questão, visto que,os feedbacks, as reformulações e as requisições de respostas gerais são reconhecidamente capazes de promover o desenvolvimento linguístico infantil, especialmente a linguagem expressiva (Girolametto, Weitzman, \& Greenberg, 2003; Fonsêca e Salomão, 2006; Leonard, Camarata, Pawlowska, Brown, \& Camarata, 2006, 2008).

A importância dos dados encontrados nos estudos citados recai no fato de os vocábulos e as pequenas frases terem sido pouco frequentes entre as doze crianças da faixa etária entre 23 e 25 meses que participaram dos contextos de interação diádica no presente estudo, uma vez que apenas duas delas se mostraram capazes de formular pequenas frases e nenhuma apresentou mais que 25 vocábulos. Estes resultados indicam a necessidade de considerar os dados da literatura, nos quais expectativa é que sejam apresentados em torno de 50 vocábulos nessa faixa etária (Rescorla, 1989, 2009). A faixa etária em questão ainda é vista como um período crítico para o desenvolvimento linguístico, pois se espera que em torno dos 24 meses de idade as crianças apresentem as suas primeiras pequenas frases, consideradas como fortes preditoras da qualidade do desenvolvimento linguístico posterior.

\section{CONSIDERAÇÕES FINAIS}

Os resultados elencados neste estudo sugerem que as educadoras apresentaram, nos contextos poliádicos, uma linguagem predominantemente diretiva, que não se associa à promoção do desenvolvimento linguístico. Diante disso, é importante salientar que são estes contextos de interação que predominam no dia a dia das creches, o que pode estar relacionado ao nível de desenvolvimento da linguagem expressiva apresentada pelas crianças durante as interações nos contextos diádicos.

Em igual escala, é necessário ponderar que o nível de desenvolvimento linguístico infantil também repercute nos estilos linguísticos utilizados pelos adultos, especialmente em sua responsividade durante as interações. Isto implica considerar que as habilidades comunicativas menos desenvolvidas pelas crianças também podem ter levado ao uso de estilos linguísticos mais simples e acessíveis pelas educadoras, como os diretivos de atenção, os assertivos e as requisições de respostas específicas, que predominaram neste estudo.

Não obstante, faz-se necessário considerar ainda aspectos contextuais mais amplos, como o fato de o desenvolvimento linguístico dessas crianças também sofrer a influência da qualidade das interações estabelecidas com as suas famílias, que se caracterizam pelo baixo nível socioeconômico. A relevância desse dado consiste na relação existente entre os níveis socioeconômicos mais baixos e o uso de uma linguagem menos diversificada e mais restritiva pelos pais, além de habilidades sintáticas menos desenvolvidas pelas crianças (Hoff, 2006) e o vocabulário menor (Hoff, 2003).

Embora o número de participantes do presente estudo tenha sido pequeno, os dados levantados se mostraram consistentes e os seus resultados corroboraram os dos outros estudos que abordaram o tema. Ademais, as pesquisadoras atentaram para a consideração dos procedimentos éticos de conduta e 
dos cuidados necessários para que a sua presença interferisse o mínimo possível nas rotinas das salas de aula. Para pesquisas futuras, faz-se importante realizar estudos que analisem as interações entre as educadoras e as crianças através de uma abordagem longitudinal, permitindo, dessa maneira, analisar as relações entre os estilos comunicativos das educadoras e o desenvolvimento linguístico infantil ao longo do tempo.

As creches públicas podem exercer o papel de agentes transformadores da qualidade do desenvolvimento das crianças que as frequentam, especialmente daquelas cujas famílias se caracterizam pelo nível socioeconômico e educacional muito baixo. Deste modo, investigar a qualidade das creches e das interações que se estabelecem nelas significa contribuir também, através de propostas de intervenção, para a promoção do desenvolvimento infantil.

\section{REFERÊNCIAS}

Braz Aquino, F. S., \& Salomão, N. M. R. (2005). Estilos diretivos maternos apresentados a meninos e meninas. Estudos de Psicologia, 10(2), 223-230.

Bressani, M. C. L., Bosa, C. A., \& Lopes, R. S. (2007). A responsividade educadora-bebê em um berçário: um estudo exploratório. Revista Brasileira de Crescimento Desenvolvimento Humano, 17(3), 21-36.

Burchinal, M. R., Roberts, J. E., Riggins, R., Jr., Zeisel, S. A., Neeb, E., \& Bryant, D. (2000). Relating quality of center-based child care to early cognitive and language development longitudinally. Child Development, 71(2) 339-357.

Cabell, S. Q., Justice, L. M., Piasta, S. B., Curenton, S. M., Wiggins, A., Turnbull, K. P., \& Petscher, Y. (2011). The impact of teacher responsivity education on preschoolers' language and literacy skills. American Journal of Speech-Language Pathology, 20, 315-330.

Clarke-Stewart, A. K., \& Allhusen, V. D. (2002). Nonparental caregiving. Em M. Bornstein (Org.), Handbook of parenting: being and becoming a parent (pp. 215-252). Mahwah, NJ: Lawrence Erlbaum Associates.

Fonseca, P. N., \& Salomão, N. M. R. (2006). Contingência semântica das falas materna e paterna: uma análise comparativa. Psicologia, Reflexão e Crítica, 19(1), 91-97.

Girolametto, L., \& Weitzman, E. (2002). Responsiveness of child care providers in interactions with toddlers and preschoolers. Language, Speech and Hearing Services in Schools, 33, 268-281.

Girolametto, L., Weitzman, E., \& Greenberg, J. (2003). Training day care staff to facilitate children's language. American Journal of Speech-Language Pathology, 12, 299-311.

Girolametto, L., Weitzman, E., Lieshout, R., \& Duff, D. (2000). Directiveness in teachers' language input to toddlers and preschoolers in day care. Journal of Speech, Language, and Hearing Research, 43, 1101-1114.
Hargrave, A. C., \& Sénéchal, M. (2000). A book reading intervention with preschool children who have limited vocabularies: the benefits of regular reading and dialogic reading. Early Childhood Research Quarterly, 15(1), 75-90.

Hoff, E. (2003). The specificity of environmental influence: socioeconomic status affects early vocabulary development via maternal speech. Child Development, 74, 1368-1378.

Hoff, E. (2006). How social contexts support and shape language development. Developmental Review, 26, 55-88.

Hoff, E., Laursen, B., \& Tardif, T. (2002). Socioeconomic status and parenting. In M. Bornstein (Org.), Handbook of Parenting: Biology and Ecology of Parenting (pp. 231-252). Hillsdale, NJ: Lawrence Erlbaum Associates.

Hunttenlocher, J., Vasilyeva, M., Cymerman, E., \& Levine, S. (2002). Language input and child syntax. Cognitive Psychology, 45, 337374.

Instituto Brasileiro de Geografia e Estatística (2007). Pesquisa Nacional por Amostra de Domicílios. Rio de Janeiro: Autor.

Instituto Nacional de Estudos e Pesquisas Educacionais Anísio Teixeira (2003). Censo dos Profissionais do Magistério da Educação Básica. Brasília: Autor.

Leonard, L. B., Camarata, Pawlowska, M., S. M., Brown, B., \& Camarata, M. N. (2006). Tense and agreement morphemes of children with in the specifc language impairment during intervention: phase 2. Journal of Speech, Language and Hearing Research, 49, 749-770.

Leonard, L. B., Camarata, Pawlowska, M., S. M., Brown, B., \& Camarata, M. N. (2008). The acquisition of tense and agreement morphemes by children with specifc language impairment: phase 3. Journal of Speech, Language and Hearing Research, 51, 120125.

Lordelo, E. R. (1998). Educadores de creche: concepções e prática. InterAÇÃ $O, 2,113-132$.

Marinac, J. V., Ozanne, A. E., \& Woodyatt, G. C. (2000). Adult language input in the early childhood educational setting. Child Language Teaching and Therapy, 16(2), 181-200.

Phillips, J. R. (1973). Syntax and vocabulary of mother's speech to young children: age and sex comparisons. Child Development, 44 , 182-185.

Rescorla, L. (1989). The language development survey a screening tool for delayed language in toddlers. Journal of Speech and Hearing Disorders, 54, 587-599.

Rescorla, L. (2009). Age 17 language and reading outcomes in latetalking toddlers: support for a dimensional perspective on language delay. Journal of Speech, Language and Hearing Research, 52(1), 16-30.

Rivera, C., Girolametto, L., Greenberg, J., \& Weitzman, E. (2005). Children's Responses to educators' questions in day care play groups. American Journal of Speech-Language Pathology, 14, 14-26.

Rowe, M. L. (2008). Child-directed speech: relation to socioeconomic status, knowledge of child development and child vocabulary skill. Journal of Child Language, 35, 185-205.

Salomão, N. M. R. (2010). Interação social e desenvolvimento linguístico. In V. Luna \& Z. Nascimento (Orgs.), Desafios da psicologia contemporânea. (pp. 91-104). João Pessoa, Paraíba, Brasil: Editora Universitária/UFPB. 
Snow, C. E. (1972). Mothers' speech to children learning language. Child Development, 43, 549-565.

Snow, C. E. (1994). Beginning from baby talk: twenty years of research on input in interaction. In C. Gallaway \& B. Richards (Orgs.), Input and interaction in language acquisition (pp. 3-12). London, England: Cambrige University Press.

Tomasello, M., Carpenter, M., Call, J., Behne, T., \& Moll, H. (2005). Understanding and sharing intentions: The origins of cultural cognition. Behavioral and Brain Sciences, 28, 675-691.
Wong, T., Moran, C., \& Foster-Cohen, S. (2012). The effects of expansions, questions and cloze procedures on children's conversational skills. Clinical Linguistics \& Phonetics, 26(3), 273-287.

\section{APÊNDICE A}

Definições das categorias e subcategorias referentes aos estilos linguísticos dirigidos às crianças pelas educadoras:

1. Assertivos (ASS): São enunciados que apresentam a intenção de descrever aspectos observáveis, como objetos, pessoas ou ações, provendo à criança informações sobre propriedades, localizações e possessões. Ex: *EDU: $O$ nome dessa boneca é Emília!

2. Reformulações (REF): São enunciados caracterizados pela subsequência e por se referirem ao tópico de fala prévia da criança. Porém, caracterizam-se também por possuírem algumas mudanças estruturais, e/ou adicionadas a novas informações. Ex: *CHI: (-)guinho? *EDU: Os amiguinhos!

3. Diretivos: Considerados comandos ou ordens que possuem caráter imperativo interpretável e dirigem o comportamento, a atenção ou as verbalizações da criança.

3.1. Diretivo de atenção (DIR:ATE): Enunciados nos quais o adulto pretende dirigir a atenção da criança, solicitando que ela se aproxime ou olhe em direção a algo. Geralmente a educadora usa o nome da criança ou palavras como "olhe", "veja” e "escute”. Ex: *EDU: Aqui “ó”! aqui, “o”! Micaela!

3.2. Diretivo de controle (DIR:CON): Enunciados através dos quais o adulto controla o comportamento da criança e/ou expressa a sua objeção ao mesmo. Ex: *EDU: Pra trás! fique lá!

3.3. Diretivo de instrução precisa (DIR:INS:PRE): Enunciados em que o adulto fornece informações precisas à criança sobre como desempenhar uma atividade/ação, nomeando objetos e/ou suas características. Ex: *EDU: Tira a mão da boca!

3.4. Diretivo de instrução imprecisa (DIR:INS:IMP): Enunciados nos quais o adulto verbaliza como desempenhar uma atividade, mas sem nomear o objeto e suas características. Ex: *EDU: Mostra quem tá aí!

4. Feedbacks: Enunciados que podem corrigir ou expressar desapontamento com o desempenho da criança no diálogo, além de aprovação ou rejeição dos enunciados incorretos das crianças.

4.1. Feedback de aprovação (FEE:APR): O adulto elogia e/ou aprova um enunciado ou uma ação da criança. Também foram considerados aqueles enunciados que repetem a fala prévia da criança por meio de uma entonação que indica aprovação. Ex: *EDU: $O$ sol, muito bem!

4.2. Feedback de desaprovação (FEE:DES): O adulto expressa verbalmente que um enunciado ou uma atividade apresentada pela criança não está correta e/ou não é esperada. Ex: *CHI: "tá” banho! *EDU: Não, banho, não...

4.3. Feedback de correção (FEE:COR): Após a emissão de um enunciado ou resposta fonologicamente e/ou de conteúdo incorreto por parte da criança, o adulto verbaliza corretamente. Ex: *EDU: Cadê o cachorrinho? *CHI: Aqui! *EDU: Não, aqui é o coelhinho!

4.4. Feedback de confirmação (FEE:CON): O adulto repete a resposta da criança, solicitando-lhe confirmação (com uma entonação marcada), demonstrando tê-la compreendido. Ex: *CHI: Dormindo... *EDU: Tá dormindo, né? 
4.5. Feedback de resposta à questão (FEE:RES): Enunciados nos quais os adultos respondem aos enunciados formuladas pelas crianças. Ex: *CHI: Olha! *EDU: Sim, tô vendo!

5. Requisições: São enunciados que demandam das crianças respostas sobre informações de objetos, situações ou ações.

5.1. Requisição de resposta específica (REQ:RES:ESP): Questões que demandam da criança uma resposta específica, afirmativa ou negativa, tais como sim/não, quero/não quero. Ex: *CHI: Olha em direção à figura na capa do livro *EDU: Ela não tem o cabelo bonito?

5.2. Requisição de resposta geral (REQ:RES:GER): Questões abertas, que demandam respostas mais elaboradas, geralmente referentes a localização, identidade ou propriedade de um objeto, evento ou situação. Ex: *EDU: $O$ passarinho foi pra onde?

5.3. Requisição de sugestão (REQ:SUG): Sugestão apresentada pelo adulto à criança, referente a uma determinada atividade durante a interação. Ex: *EDU: Vamos ver, você sozinha, o livrinho?

5.4. Requisição de esclarecimento (REQ:ESC): Enunciados que solicitam esclarecimento ou confirmação do enunciado precedente da criança, que indique o não entendimento por parte do adulto. Ex: *CHI: Ó, o sol! *EDU: $O$ que? isso aqui?

5.5. Requisição de complementação (REQ:COM): $\mathrm{O}$ adulto solicita que a criança complete o seu enunciado ou sentença. Ex: *EDU: Ela tá brincando aonde? no par+...

6. Imitações (IMI:AD): Enunciados subsequentes à fala prévia da criança, imitando-a de forma exata. Ex: *CHI: ()mendo! *EDU: (-)mendo...

7. Expressão de afeto: Meios utilizados pelos adultos para demonstrar afeição pelas crianças.

7.1. Acariciar $(A C)$ : Demonstrações afetivas envolvendo contatos físicos entre adulto e criança, tais como: afagar, por no colo, abraçar e/ou beijar. Ex: *EDU: 0. \%act: senta no chão e põe a criança no colo.

7.2. Sorrir (SOR): O adulto expressa-se durante a interação com a criança através do sorriso. Ex: *EDU: 0. \%act: olha em direção à criança e sorri. 